\title{
Persepsi Pasien dengan Keluhan Minor Illness terhadap Peran Apoteker Terkait Efisiensi Biaya dan Akses Pengobatan di Era Jaminan Kesehatan Nasional
}

\author{
Perceptions of Patients with Minor Illness Complaints \\ on the Role of Pharmacists Regarding Cost Efficiency \\ and Access to Medicines in the Era of National Health Insurance
}

\author{
$\operatorname{Irmin}^{1^{*}}$, Prih Sarnianto ${ }^{1}$, Yusi Anggriani ${ }^{1}$, Jenny Pontoan ${ }^{2}$ \\ ${ }^{1}$ Fakultas Farmasi, Universitas Pancasila, \\ JI. Srengseng Sawah, Jagakarsa, Jakarta Selatan, DKI Jakarta 12640, Indonesia \\ ${ }^{2}$ Fakultas Farmasi, Institut Sains dan Teknologi Nasional, \\ Jl. Srengseng Sawah, Jagakarsa, Srengseng Sawah, Jagakarsa, Jakarta Selatan, DKI \\ Jakarta, 12630, Indonesia \\ *Corresponding author email: irminapoteker@gmail.com
}

Received 30-09-2019 Accepted 11-06-2020 Available online 01-07-2020

\begin{abstract}
ABSTRAK
Minor Illness adalah kondisi medis yang kurang serius yang tidak memerlukan tes laboratorium atau tes darah. Minor illness juga didefinisikan sebagai kondisi yang akan hilang dengan sendirinya dan dapat sembuh dengan melakukan pengobatan sendiri (swamedikasi). Kebanyakan pasien dapat mengobati penyakit minor illness hanya dengan menggunakan obat-obat OTC (Over-the-Counter). Penelitian ini bertujuan untuk mengetahui persepsi pasien dengan keluhan minor illness terhadap peran apoteker terkait efisiensi biaya obat dan akses pengobatan di era JKN (Jaminan Kesehatan Nasional). Penelitian ini dapat memberikan masukan bagi pemerintah dalam hal ini BPJS (Badan Penyelenggara Jaminan Sosial) sebagai otoritas pelaksana program JKN terkait pentingnya peran apoteker dalam melakukan efisiensi biaya dan kemudahan akses pengobatan pasien dengan keluhan penyakit minor illness. Penelitian ini menggunakan metode observasi dengan pengolahan data secara deskriptif. Penelitian ini dilakukan di apotek yang bekerjasama dengan BPJS di wilayah DKI, dengan sampel sebanyak 99 responden pasien yang melakukan swamedikasi pada bulan Juni 2018. Hasil penelitian menunjukkan bahwa terdapat potensi efisiensi biaya baik dari aspek manajemen, klinis, swamedikasi yang efektif dan terdapat kemudahan akses pengobatan melalui swamedikasi. Kesimpulan, keterlibatan apoteker dalam menangani keluhan minor illness terbukti menghemat biaya dan kemudahan akses pengobatan.
\end{abstract}

Kata kunci: efisiensi biaya, minor illness, peran apoteker, persepsi pasien. 


\begin{abstract}
Minor illness is a less serious medical condition that does not require laboratory tests or blood tests. Minor illness is also defined as a condition that will go away on its own and can be cured by self-medication. Most patients can treat minor illnesses only by using OTC (Over-the-Counter) medications. This study aims to determine the perception of patients with minor illness complaints on the role of pharmacists related to the efficiency of drug costs and access to treatment in the National Health Insurance (Jaminan Kesehatan Nasional, JKN) era. This research can provide input for the government, in this case, the Social Security Administrator for Health (Badan Penyelenggara Jaminan Sosial/BPJS), as the JKN program implementing authority related to the important role of pharmacists in cost efficiency and ease of access to treatment of patients with complaints of minor illness. This research uses an observation method with descriptive data processing. This research was conducted at a pharmacy that collaborated with BPJS in the DKI Jakarta region, with a sample of 99 respondents who did self-medication in June 2018. The results showed that there were potential cost efficiencies in terms of effective management, clinical, effective self-medication, and easiness of access treatment through self-medication. In conclusion, the involvement of pharmacists in handling complaints of minor illness has been proven to save costs and ease of access to treatment.
\end{abstract}

Key words: cost efficiency, minor illness, patient perception, role of pharmacists.

\section{Pendahuluan}

Minor illness adalah kondisi medis yang kurang serius yang tidak memerlukan tes laboratorium atau tes darah. Minor illness juga didefinisikan sebagai kondisi yang akan hilang dengan sendirinya dan dapat sembuh dengan melakukan pengobatan sendiri (swamedikasi). Kebanyakan pasien dapat mengobati penyakit minor illness hanya dengan menggunakan obat-obat OTC (Over-the-Counter) (Kristina, 2007; Abay

\& Amelo, 2010). Upaya pencarian pengobatan yang dilakukan oleh masyarakat dengan keluhan sakit ialah melalui pengobatan sendiri atau swamedikasi yakni sebesar $(87,37 \%)$, hal ini terkait dengan harga obat resep dokter yang relatif lebih mahal dibandingkan obat bebas. Selain itu pengobatan swamedikasi juga memberikan nilai tambah kepada pasien berupa penggunaan obat yang aman bila digunakan sesuai aturan, efektif menghilangkan keluhan sakit yang bersifat self-limiting, efisiensi waktu dan biaya, serta pasien dapat berperan dalam keputusan terapi (Kristina et al., 2007). Penyediaan dan pemberian obat dilakukan oleh apotek yang telah melakukan kerjasama dengan BPJS (Badan Penyelenggara Jaminan Sosial) sebagai bagian dari FKTP (Fasilitas Kesehatan Tingkat Pertama). Hal ini menjadi tantangan bagi apoteker agar mampu melakukan pelayanan kefarmasian yang bermutu dan cost effective melalui pelayanan langsung atau swamedikasi kepada pasien sesuai dengan kompetensi apoteker dalam 
melakukan pelayanan kefarmasian baik dari aspek manajemen farmasi maupun pelayanan farmasi klinis sesuai dengan Permenkes No. 73 tahun 2016 tentang Standar Pelayanan Kefarmasian di Apotek.

Peningkatan peran dan pemanfaatan kompetensi apoteker serta sarana apotek FKTP melalui swamedikasi kepada pasien dengan keluhan minor illness diharapkan dapat mengurangi biaya pengobatan dan memberikan kemudahan akses kepada pasien minor illness dalam pelaksanaan JKN di Indonesia (Susanti et al., 2014). Berdasarkan hal tersebut, maka peneliti ingin mengetahui pendapat pasien dengan keluhan minor illness peserta BPJS terhadap efisiensi biaya obat dan akses pengobatan di era JKN. Penelitian ini dapat memberikan masukan bagi pemerintah dalam hal ini BPJS sebagai otoritas pelaksana program JKN terkait pentingnya peran apoteker dalam melakukan efisiensi biaya dan kemudahan akses pengobatan pasien dengan keluhan penyakit minor illness.

\section{Metode Penelitian}

Penelitian dilakukan menggunakan metode observasi pada 34 apotek yang bekerjasama dengan BPJS di wilayah DKI Jakarta, dengan total populasi sebanyak 6.800 kunjungan pasien/bulan. Pengambilan data dilakukan pada bulan Juni 2018 menggunakan kuesioner. Pasien dengan kriteria inklusi adalah pasien peserta BPJS dengan keluhan minor illness yakni pilek, demam, flu, dan sakit kepala, atau pernah mengalami keluhan tersebut. Kriteria eksklusi adalah pasien yang telah mengisi kuesioner tapi datanya tidak lengkap, atau pasien yang tidak bersedia mengisi kuesioner. Pasien diminta untuk mengisi kuesioner tersebut dengan tujuan untuk mengetahui persepsi pasien terkait efisiensi biaya dan akses pengobatan dalam pelaksanaan program JKN.

\section{Analisis Data}

Data yang digunakan dalam penelitian ini merupakan data primer yang diperoleh melalui pengisian kuesioner pasien dengan keluhan penyakit minor illness peserta BPJS di wilayah DKI Jakarta. Uji validitas dan reliabilitas kuesioner dilakukan terhadap 30 pasien dengan keluhan minor illness yang berkunjung ke apotek. Jumlah pasien tersebut tidak termasuk dalam responden penelitian. Hasil validitas menunjukkan bahwa semua pertanyaan dinyatakan valid, karena nilai $r$ hitung $(0,388-0,822)$ lebih dari $r$ tabel $(0,361)$. Nilai koefisien reliabilitas 0,882 di atas standar yang ditetapkan yaitu 0,6 sehingga dinyatakan reliabel. Selanjutnya dilakukan analisis deskriptif dan hasil penelitian ditampilkan dalam bentuk tabel dan grafik. Kategori efektivitas biaya dianalisis berdasarkan nilai rata-rata distribusi frekuensi dengan pedoman sebagai berikut: nilai minimum $=1$, nilai maksimum=3, interval $=(3-1) / 3=0,67$, dan nilai 0,1 sebagai pembeda nilai batas atas dan batas bawah, sehingga diperoleh kategori tidak efektif=1-1,7; kurang efektif=1,8-2,3; dan efektif=2,4-3. 


\section{Hasil dan Pembahasan}

Karakteristik Responden

Karakteristik responden yang diteliti meliputi jenis kelamin, umur, pendidikan terakhir, dan pekerjaan. Karakteristik responden pasien apotek yang menjadi sampel dalam penelitian ini berjenis kelamin wanita sebanyak 50 orang $(50,5 \%)$, pria sebanyak 49 (49,5\%), kisaran umur antara 17 sampai 72 tahun dengan rata-rata umur 35,4 tahun, berpendidikan SMA sebanyak 45 orang $(45,4 \%)$, SD sebanyak 20 orang $(20,2 \%)$, Perguruan tinggi $(16,2 \%)$, SMP sebanyak 15 orang $(15,2 \%)$, dan tidak sekolah sebanyak 3 orang $(3,0 \%)$. Serta untuk data pekerjaan, secara berturut-turut yakni bekerja lain-lain yakni 29 orang $(29,3 \%)$, sebagai pegawai swasta 28 orang $(28,3 \%)$, wiraswasta sebanyak 21 orang (21,2\%), IRT (Ibu Rumah Tangga) sebanyak 14 orang $(14,1 \%)$, PNS (Pegawai Negeri Sipil) sebanyak 5 orang $(5,1 \%)$ dan pelajar/mahasiswa 2 orang $(2,0 \%)$. Pekerjaan lain-lain responden pasien apotek yakni pemulung, tukang ojek/becak, sopir angkot, tukang parkir, buruh kasar, dan serabutan. Persentase di atas menunjukan bahwa responden masih dalam usia produktif. Hal ini berdampak pada berkurangnya waktu kerja karena digunakan untuk mendapatkan pelayanan kesehatan di FKTP, dimana menurut hasil kajian CHEPS (Center for Health Economics and Policy Studies) UI tahun 2016, salah satu masalah yang terjadi dalam pelaksanaan JKN adalah waktu antrian yang cukup panjang dalam mendapatkan pelayanan kesehatan, sehingga menurunkan produktifitas dan meningkatkan indirect cost yang harus ditanggung oleh pasien.

Potensi Efisiensi Biaya dari Aspek Manajemen

Potensi efisiensi biaya dari aspek manajemen dapat dilihat pada Tabel 1. Hasil penelitian menunjukkan bahwa persepsi responden yang menilai biaya dari aspek manajemen dalam kategori efektif sebanyak 88,9\%; kurang efektif sebanyak 9,1\%; dan tidak efektif sebanyak $2,0 \%$.

Tabel 1. Gambaran potensi efisiensi biaya dari aspek manajemen

\begin{tabular}{lccc}
\hline \multicolumn{1}{c}{ Item Pertanyaan } & Ya & Tidak & Kurang Tahu \\
\hline $\begin{array}{l}\text { 5.1 Apakah Bapak/lbu mendapatkan obat di apotek dengan } \\
\text { harga yang terjangkau }\end{array}$ & $91(91,9 \%)$ & $4(4,0 \%)$ & $4(4,0 \%)$ \\
$\begin{array}{l}\text { 5.2 Apakah obat yang Bapak/Ibu dapatkan adalah obat } \\
\text { legal dari penyalur yang resmi }\end{array}$ & $57(57,6 \%)$ & $8(8,1 \%)$ & $34(34,35 \%)$ \\
$\begin{array}{l}\text { 5.3 Apakah Bapak/Ibu mendapatkan obat di apotek sesuai } \\
\text { dengan yang diinginkan }\end{array}$ & $90(90,9 \%)$ & $0(0,0 \%)$ & $9(9,1 \%)$ \\
5.4 Apakah obat yang Bapak/lbu inginkan selalu tersedia & $88(88,9 \%)$ & $5(5,1 \%)$ & $6(6,1 \%)$ \\
5.5 Apakah obat yang Bapak/lbu terima di apotek dalam & $97(98,0 \%)$ & $0(0,0 \%)$ & $2(2,0 \%)$ \\
keadaan yang baik & & & \\
Rata-Rata Distribusi Frekuensi & $88(88,9 \%)$ & \\
Efektif & $9(9,1 \%)$ & \\
Kurang Efektif & $2(2,00 \%)$ & \\
Tidak Efektif & & \\
\hline
\end{tabular}


Berdasarkan hal tersebut, pasien dengan keluhan minor illness yang datang berobat ke apotek merasakan manfaat aspek manajemen pelayanan kefarmasian yang dilakukan oleh apoteker di apotek, meskipun pada pertanyaan apakah obat didapatkan dari penyalur resmi hanya terdapat $57,6 \%$ pasien yang yakin, $34,3 \%$ menjawab kurang tahu, dan $8,1 \%$ pasien menjawab tidak. Hal ini menjadi tantangan bagi apoteker untuk dapat memberikan edukasi kepada pasien bahwa apotek merupakan fasilitas kesehatan yang pelayanannya mempunyai standar, baik dari aspek manajemen maupun klinis (Kementerian Kesehatan, 2016).

Analisis efektifitas pelayanan farmasi dari aspek manajemen dengan menggunakan distribusi frekuensi pada Tabel 1, terlihat bahwa potensi efisiensi biaya dalam kategori efektif $(88,9 \%)$, kurang efektif $(9,1 \%)$, dan tidak efektif $(2,0 \%)$. Hal ini menunjukkan bahwa apoteker dapat melakukan efisiensi biaya dari aspek manajemen pelayanan kefarmasian kepada pasien di apotek.

Standar operasional pelayanan yang ada di apotek diterapkan mulai dari pemesanan obat, penerimaan, penyimpanan, pelayanan obat kepada pasien dengan pemilihan obat yang tepat. Hal tersebut dapat mendorong masyarakat melakukan swamedikasi sehingga penjualan obat bebas dan obat bebas terbatas di apotek mengalami peningkatan mencapai 30 , peningkatan penjualan ini juga dikarenakan saat melakukan swamedikasi pasien diberikan informasi tentang pemilihan obat yang sesuai dengan kondisi pasien dan pemilihan obat dengan harga yang terjangkau sehingga meningkatkan pasien untuk beralih membeli obat ke apotek (Restiyono, 2016).

Potensi Efisiensi Biaya dari Aspek Klinis

Potensi efisiensi biaya dari aspek

klinis digambarkan pada Tabel 2 . Diketahui bahwa pasien setuju untuk dilakukan pelayanan farmasi klinis oleh apoteker guna meningkatkan efisiensi biaya, meningkatkan pemahaman pasien tentang penggunaan obat yang baik dan manfaat pengobatan. Hal ini sejalan dengan penelitian yang dilakukan oleh Gunawan et al. (2017) dimana apoteker dapat meningkatkan efisiensi biaya pengobatan melalui pengkajian resep dan intervensi pengobatan sehingga dapat mengurangi atau menghemat biaya pengobatan yang sangat penting dalam mendukung pelaksanaan program JKN.

Berdasarkan analisis efektifitas biaya dengan menggunakan distribusi frekuensi seperti pada Tabel 2, diketahui bahwa persepsi pasien menilai potensi efektifitas biaya dari aspek klinis dalam kategori efektif $(78,8 \%)$, kurang efektif $(19,2 \%)$, dan tidak efektif $(4,0)$. Hal ini menunjukkan bahwa apoteker dapat meningkatkan efektifitas biaya pengobatan bagi pasien melalui pelayanan farmasi klinis yang diberikan kepada pasien di apotek.

Oleh karena itu, peran apoteker sangat diperlukan untuk dapat berpartisipasi dalam pelaksanaan JKN sesuai dengan kompetensi yang dimiliki agar dapat meningkatkan efisiensi biaya 
dari aspek klinis pelayan kefarmasian outcome kesembuhan bagi pasien. serta berdampak pada meningkatnya

Tabel 2. Gambaran potensi efisiensi biaya dari aspek klinis

\begin{tabular}{|c|c|c|c|c|}
\hline \multicolumn{2}{|r|}{ Item } & \multirow{2}{*}{$\begin{array}{c}\text { Ya } \\
85(85,9 \%)\end{array}$} & \multirow{2}{*}{$\begin{array}{c}\text { Tidak } \\
8(8,1 \%)\end{array}$} & \multirow{2}{*}{$\begin{array}{c}\begin{array}{c}\text { Kurang } \\
\text { Tahu }\end{array} \\
6(6,1 \%)\end{array}$} \\
\hline & $\begin{array}{l}\text { Apakah Bapak/Ibu setuju obat yang telah } \\
\text { diresepkan dikaji kembali oleh apoteker }\end{array}$ & & & \\
\hline & Meringankan biaya pengobatan & $81(95,3 \%)$ & $2(2,4 \%)$ & $2(2,4 \%)$ \\
\hline & Rasional pengobatan & $71(83,5 \%)$ & $0(0,0 \%)$ & $14(16,5 \%)$ \\
\hline & Manfaat pengobatan & $81(95,3 \%)$ & $0(0,0 \%)$ & $4(4,7 \%)$ \\
\hline \multirow[t]{4}{*}{5.7} & $\begin{array}{l}\text { Apakah Bapak/lbu setuju apoteker melakukan } \\
\text { edukasi pemberian informasi obat saat } \\
\text { menyerahkan obat ke Bapak/lbu }\end{array}$ & $92(92,9 \%)$ & $4(4,0 \%)$ & $3(3,0 \%)$ \\
\hline & $\begin{array}{l}\text { Apakah edukasi pemberian informasi obat } \\
\text { oleh apoteker telah dilakukan dengan } \\
\text { akurat dan baik }\end{array}$ & $84(91,3 \%)$ & $0(0,0 \%)$ & $8(8,7 \%)$ \\
\hline & $\begin{array}{l}\text { Apakah edukasi pemberian informasi obat } \\
\text { oleh apoteker, memberikan rekomendasi } \\
\text { pengobatan yang objektif }\end{array}$ & $75(81,5 \%)$ & $1(1,1 \%)$ & $16(17,4 \%)$ \\
\hline & $\begin{array}{l}\text { Apakah edukasi informasi obat oleh } \\
\text { apoteker dapat di mengerti dengan baik }\end{array}$ & $88(95,7 \%)$ & $0(0,0 \%)$ & $4(4,3 \%)$ \\
\hline \multirow[t]{4}{*}{5.8} & $\begin{array}{l}\text { Apakah bapak/ibu setuju untuk gejala } \\
\text { penyakit yang bapak/ibu alami perlu } \\
\text { dilakukan konseling oleh apoteker }\end{array}$ & $68(68,7 \%)$ & $19(19,2 \%)$ & $12(12,1 \%)$ \\
\hline & $\begin{array}{l}\text { Mendapatkan informasi tentang keluhan } \\
\text { penyakit yang dirasakan }\end{array}$ & $64(94,1 \%)$ & $2(2,9 \%)$ & $2(2,9 \%)$ \\
\hline & $\begin{array}{l}\text { Mendapatkan penjelasan tentang cara } \\
\text { penggunaan obat yang baik dan benar }\end{array}$ & $68(100 \%)$ & $0(0,0 \%)$ & $0(0,0 \%)$ \\
\hline & $\begin{array}{l}\text { Mendapatkan informasi tentang efek } \\
\text { samping obat }\end{array}$ & $66(97,1 \%)$ & $2(2,9 \%)$ & $0(0,0 \%)$ \\
\hline 5.9 & Lain-lain & $52(76,5 \%)$ & $0(0,0 \%)$ & $16(23,5 \%)$ \\
\hline \multicolumn{5}{|c|}{ Rata-Rata Distribusi Frekuensi } \\
\hline \multicolumn{2}{|c|}{ Efektif } & $76(76,8 \%)$ & & \\
\hline \multicolumn{2}{|c|}{ Kurang Efektif } & $19(19,2 \%)$ & & \\
\hline \multicolumn{2}{|c|}{ Tidak Efektif } & $4(4,0 \%)$ & & \\
\hline
\end{tabular}

Hasil penelitian ini menunjukkan bahwa apoteker telah menerapkan kegiatan pelayanan farmasi klinis di apotek sesuai standar pelayanan kefarmasian (Kementerian Kesehatan, 2016). Hal ini sejalan dengan penelitian yang dilakukan Restiyono (2016) di apotek wilayah Kajen, Kabupaten Pekalongan, dimana pada waktu melayani penjualan obat bebas dan obat bebas terbatas sudah disertai infomasi tentang pemilihan obat sesuai dengan kondisi pasien, cara minum, aturan minum, cara penyimpanan, dan pemilihan obat yang terjangkau oleh pasien. Sehingga hal tersebut telah mendorong masyarakat untuk beralih melakukan pengobatan sendiri ke apotek. 
Pada penelitian yang dilakukan di wilayah Bantul, diketahui bahwa sebagian besar responden telah mengetahui aturan pakai obat (72\%), dan hanya $28 \%$ tidak mengetahui aturan pakai obat. Konsumen yang mengetahui aturan pakai obat kemungkinan telah beberapa kali membeli obat yang sama untuk indikasi yang sama ataupun telah beberapa kali membaca label kemasan obat yang sama. Sedangkan konsumen yang tidak mengetahui aturan pakai kemungkinan baru pertama kali membeli obat untuk indikasi tertentu sehingga belum mengetahui aturan pakai obat tersebut (Candradewi \& Kristina, 2017).
Potensi Efisiensi Biaya dari Aspek Swamedikasi

Potensi efisiensi biaya dari aspek swamedikasi dapat dilihat pada Tabel 3. Hasil penelitian menunjukkan bahwa persepsi responden yang menilai biaya melalui pengobatan langsung oleh apoteker dalam kategori efektif sebanyak 76,8\%, kurang efektif yakni sebanyak 13,1\%, dan tidak efektif sebanyak $10,1 \%$. Data ini menunjukkan bahwa pasien minor illness menilai pengobatan swamedikasi yang dilakukan oleh apoteker biayanya lebih murah.

Tabel 3. Gambaran potensi efektifitas biaya melalui swamedikasi oleh apoteker

\begin{tabular}{|c|c|c|c|c|}
\hline & Item & Ya & Tidak & Kurang Tahu \\
\hline 5.9 & $\begin{array}{l}\text { Apakah Bapak/lbu setuju untuk penyakit minor illness, } \\
\text { dapat dilakukan pengobatan langsung oleh apoteker } \\
\text { di apotek tanpa melalui resep dokter }\end{array}$ & $\begin{array}{c}62 \\
(62,6 \%)\end{array}$ & $\begin{array}{c}16 \\
(16,2 \%)\end{array}$ & $\begin{array}{c}21 \\
(21,2 \%)\end{array}$ \\
\hline 5.10 & $\begin{array}{l}\text { Apakah Bapak/lbu merasakan manfaat pengobatan } \\
\text { oleh apoteker di apotek sesuai dengan keluhan yang } \\
\text { dirasakan }\end{array}$ & $\begin{array}{c}89 \\
(89,9 \%)\end{array}$ & $\begin{array}{c}0 \\
(0,0 \%)\end{array}$ & $\begin{array}{c}10 \\
(10,1 \%)\end{array}$ \\
\hline 5.11 & $\begin{array}{l}\text { Apakah menurut Bapak/lbu, dengan melakukan } \\
\text { pengobatan langsung ke apoteker, biaya pengobatan } \\
\text { yang dikeluarkan jadi lebih murah }\end{array}$ & $\begin{array}{c}62 \\
(62,6 \%)\end{array}$ & $\begin{array}{c}5 \\
(5,1 \%)\end{array}$ & $\begin{array}{c}32 \\
(32,3 \%)\end{array}$ \\
\hline 5.12 & $\begin{array}{l}\text { Apakah menurut Bapak/lbu, dengan melakukan } \\
\text { pengobatan langsung ke apoteker, akan meringankan } \\
\text { biaya karena pelayanan yang lebih cepat }\end{array}$ & $\begin{array}{c}85 \\
(85,9 \%)\end{array}$ & $\begin{array}{c}2 \\
(2,0 \%)\end{array}$ & $\begin{array}{c}12 \\
(12,1 \%)\end{array}$ \\
\hline 5.13 & $\begin{array}{l}\text { Apakah menurut Bapak/lbu dengan melakukan } \\
\text { pengobatan langsung ke apoteker, Bapak/lbu merasa } \\
\text { terlibat dalam pemilihan obat yang sesuai dengan } \\
\text { yang diinginkan }\end{array}$ & $\begin{array}{c}79 \\
(79,8 \%)\end{array}$ & $\begin{array}{c}6 \\
(6,1 \%)\end{array}$ & $\begin{array}{c}14 \\
(14,1 \%)\end{array}$ \\
\hline 5.14 & $\begin{array}{l}\text { Apakah menurut Bapak/lbu, pelayanan pengobatan } \\
\text { oleh apoteker dapat meringankan keterbatasan } \\
\text { tenaga kesehatan }\end{array}$ & $\begin{array}{c}65 \\
(65,7 \%)\end{array}$ & $\begin{array}{c}8 \\
(8,1 \%)\end{array}$ & $\begin{array}{c}26 \\
(26,3 \%)\end{array}$ \\
\hline 5.15 & $\begin{array}{l}\text { Apakah menurut Bapak/lbu, pelayanan pengobatan } \\
\text { oleh apoteker dapat meringankan keterbatasan } \\
\text { sarana kesehatan }\end{array}$ & $\begin{array}{c}64 \\
(64,6 \%)\end{array}$ & $\begin{array}{c}7 \\
(7,1 \%)\end{array}$ & $\begin{array}{c}28 \\
(28,3 \%)\end{array}$ \\
\hline \multicolumn{5}{|c|}{ Rata-Rata Distribusi Frekuensi } \\
\hline \multicolumn{2}{|c|}{ Efektif } & \multicolumn{3}{|l|}{$76(76,8 \%)$} \\
\hline \multicolumn{2}{|c|}{ Kurang Efektif } & \multicolumn{3}{|l|}{$13(13,1 \%)$} \\
\hline \multicolumn{2}{|c|}{ Tidak Efektif } & $10(10,1 \%)$ & & \\
\hline
\end{tabular}


Konsumen dalam melakukan swamedikasi sebagian besar informasi mengenai penggunaan obat diperoleh dari iklan di televisi (Widayati, 2013). Pelaksanaan swamedikasi hendaknya sesuai dengan kriteria penggunaan obat yang rasional, yaitu tepat obat, tepat pasien, tepat dosis, waspada efek samping obat, tidak ada interaksi obat yang bermakna secara klinis, dan tidak ada duplikasi obat.

Hal-hal yang mendorong melakukan swamedikasi di antaranya tidak melakukan pemeriksaan penyakit kepada dokter dikarenakan gejala penyakit yang dialami masih ringan $(46,4 \%)$, kesulitan menemui dokter
(22,5\%), tidak ada waktu (11,6\%), biaya medis terlalu tinggi $(11,6 \%)$. Sedangkan pengetahuan mengenai swamedikasi didasari dari pengalaman pribadi (51,2\%), saran teman $(27,7 \%)$, dan majalah atau iklan (2\%) (Lei \& Jiang, 2018).

Kemudahan Akses Pengobatan melalui Swamedikasi

Kemudahan akses pengobatan melalui pelayanan swamedikasi, dapat dilihat pada Tabel 4. Hasil penelitian menunjukkan bahwa apoteker yang berpraktek di apotek dapat memberikan kemudahan akses pelayanan kesehatan kepada pasien dengan keluhan minor illness.

Tabel 4. Gambaran kemudahan akses pengobatan melalui swamedikasi

\begin{tabular}{|c|c|c|c|}
\hline Item & Ya & Tidak & $\begin{array}{c}\text { Kurang } \\
\text { Tahu }\end{array}$ \\
\hline $\begin{array}{l}\text { 6.1 Apakah menurut Bapak/lbu, biaya yang dikeluarkan } \\
\text { untuk mencapai apotek lebih meringankan bila } \\
\text { dibandingkan ke sarana kesehatan lain }\end{array}$ & $\begin{array}{c}85 \\
(85,9 \%)\end{array}$ & $\begin{array}{c}4 \\
(4,0 \%)\end{array}$ & $\begin{array}{c}10 \\
(10,1 \%)\end{array}$ \\
\hline $\begin{array}{l}\text { 6.2 Apakah menurut Bapak/Ibu, jarak apotek kerjasama } \\
\text { BPJS dengan tempat tinggal Bapak/Ibu relatif lebih dekat }\end{array}$ & $\begin{array}{c}68 \\
(68,7 \%)\end{array}$ & $\begin{array}{c}12 \\
(12,1 \%)\end{array}$ & $\begin{array}{c}19 \\
(19,2 \%)\end{array}$ \\
\hline $\begin{array}{l}\text { 6.3 Apakah menurut Bapak/lbu, sarana transportasi untuk } \\
\text { menuju apotek kerjasama BPJS tersedia dengan baik }\end{array}$ & $\begin{array}{c}72 \\
(72,7 \%)\end{array}$ & $\begin{array}{c}12 \\
(12,1 \%)\end{array}$ & $\begin{array}{c}15 \\
(15,2 \%)\end{array}$ \\
\hline $\begin{array}{l}\text { 6.4 Apakah menurut Bapak/lbu, apoteker adalah salah satu } \\
\text { tenaga kesehatan yang mudah untuk diakses/ditemui }\end{array}$ & $\begin{array}{c}88 \\
(88,9 \%)\end{array}$ & $\begin{array}{c}4 \\
(4,0 \%)\end{array}$ & $\begin{array}{c}7 \\
(7,1 \%)\end{array}$ \\
\hline $\begin{array}{l}\text { 6.5 Apakah menurut Bapak/lbu, waktu pelayanan } \\
\text { pengobatan oleh apoteker lebih singkat dan cepat bila } \\
\text { dibandingkan dengan tenaga kesehatan lain }\end{array}$ & $\begin{array}{c}82 \\
(82,8 \%)\end{array}$ & $\begin{array}{l}1 \\
(1,0 \%)\end{array}$ & $\begin{array}{c}16 \\
(16,2 \%)\end{array}$ \\
\hline $\begin{array}{l}\text { 6.6 Apakah menurut Bapak/lbu, apoteker memiliki } \\
\text { pengetahuan yang baik dalam melakukan pelayanan }\end{array}$ & $\begin{array}{c}92 \\
(92,9 \%)\end{array}$ & $\begin{array}{c}0 \\
(0,0 \%)\end{array}$ & $\begin{array}{c}7 \\
(7,1 \%)\end{array}$ \\
\hline $\begin{array}{l}\text { 6.7 Apakah menurut Bapak/lbu, apoteker memiliki } \\
\text { kepercayaan diri yang baik dalam melakukan pelayanan }\end{array}$ & $\begin{array}{c}92 \\
(92,9 \%)\end{array}$ & $(2,0 \%)$ & $\begin{array}{c}5 \\
(5,1 \%)\end{array}$ \\
\hline $\begin{array}{l}\text { 6.8 Apakah menurut Bapak/lbu, apoteker memiliki empati } \\
\text { yang baik dalam melakukan pelayanan }\end{array}$ & $\begin{array}{c}84 \\
(84,8 \%)\end{array}$ & $\begin{array}{c}6 \\
(6,1 \%)\end{array}$ & $\begin{array}{c}9 \\
(9,1 \%)\end{array}$ \\
\hline $\begin{array}{l}\text { 6.9 Apakah menurut Bapak/lbu, apoteker ramah dalam } \\
\text { melakukan pelayanan obat }\end{array}$ & $\begin{array}{c}86 \\
(86,9 \%)\end{array}$ & $\begin{array}{c}6 \\
(6,1 \%)\end{array}$ & $\begin{array}{c}7 \\
(7,1 \%)\end{array}$ \\
\hline
\end{tabular}


Kemudahan akses pelayanan kesehatan dinilai dari mudahnya Faskes dicapai oleh masyarakat, tidak terhalang oleh keadaan geografis, sosial, ekonomi, organisasi, dan bahasa (Pohan, 2004). Swamedikasi muncul didasari pemikiran pada masyarakat bahwa pengobatan sendiri dapat menyembuhkan penyakit ringan tanpa melibatkan tenaga kesehatan. Alasan lainnya adalah karena keterbatasan biaya untuk berobat ke dokter, ketiadaan waktu untuk ke dokter, dan akses ke pelayanan kesehatan yang minim. Berdasarkan Riset Kesehatan Dasar yang dilakukan oleh Badan Peneliti dan Pengembangan Kementerian Kesehatan RI pada tahun 2013 menunjukkan bahwa sebanyak $35,2 \%$ rumah tangga di Indonesia menyimpan obat untuk swamedikasi (Kementerian Kesehatan, 2013).

Apoteker memiliki peran dalam konseling konsumen mengenai pengobatan, baik obat yang menggunakan resep maupun obat tanpa resep atau obat bebas dan bebas terbatas (OTC) (Villako et al., 2012). Harapan konsumen paling besar dalam pembelian obat tanpa resep adalah mendapatkan konseling secara profesional oleh apoteker, dan mendapatkan rekomendasi dalam pemilihan obat. Konsumen yang pernah mendapatkan konseling dalam swamedikasi merasa puas terhadap konseling yang diberikan oleh apoteker, dengan demikian apoteker memiliki peranan penting dan dibutuhkan dalam swamedikasi. Pasien merasa terbantu dengan adanya partisipasi dari apoteker dalam membantu memilihkan obat yang tepat bagi mereka. Oleh karena itu apoteker sebaiknya tidak perlu menunggu konsumen meminta namun lebih proaktif dalam memberikan pelayanan kepada pasien dalam pemilihan obat tanpa resep (Halila et al., 2015).

\section{Daftar Pustaka}

Abay, S.M., Amelo, W. 2010. Assessment of self-medication practices among medical, pharmacy, and health science students in Gondar University, Ethiopia. J Young Pharm, 2(3):308-310.

Candradewi, S.F., Kristina, S.A. 2017. Gambaran pelaksanaan swamedikasi dan pendapat konsumen apotek mengenai konseling obat tanpa resep di wilayah Bantul. Pharmaciana, 7(1):41-52.

Gunawan, C.A., Pribadi, F., Risdian, I. 2017. Analisis efisiensi obat setelah dilakukan telaah resep dan intervensi apoteker dalam pelayanan farmasi pasien JKN rawat jalan di RS PKU Muhammadiyah Yogyakarta. Proceeding Health Architecture, 1(1):35-44.

Halila, G.C., Junior, E.H., Otuki, M.F., Correr, C.J. 2015. The practice of OTC counseling by community pharmacists in Parana, Brazil. Pharmacy Practice, 13(4):597.

Peraturan Menteri Kesehatan Republik Indonesia Nomor 73 Tahun 2016 tentang Standar Pelayanan Kefarmasian di Apotek. 
Kementerian Kesehatan Republik Indonesia. 2013. Riset Kesehatan Dasar. Jakarta: Badan Penelitian dan Pengembangan Kesehatan.

Kristina, S.A., Prabandari, Y.S., Sudjaswadi, R. 2007. Perilaku pengobatan sendiri yang rasional pada masyarakat. Berita Kedokteran Masyarakat, 23(4):176-183.

Lei, X., Jiang, H. 2018. Self-medication practice and associated factors among residents in Wuhan China. International Journal of Environmental Research and Public Health, 15(2):1-10.

Susanti, I.M.P., Nugraha, I.S., Wirasuta, I.M.A.G., Diantari, N.M.D. 2014. Studi peran apoteker sebagai verifikator dalam pelaksanaan asuhan kefarmasian pasien rawat jalan peserta PT. Askes (Persero) cabang Denpasar di RSUD Wangaya. Jurnal Farmasi Udayana, 3(1):87-90.
Pohan. 2004. Jaminan Mutu Pelayanan Kesehatan: Dasar Pengertian dan Penerapan. Jakarta: EGC .

Restiyono, A. 2016. Analisis faktor yang berpengaruh dalam swamedikasi antibiotik pada ibu rumah tangga di Kelurahan Kajen Kebupaten Pekalongan. Jurnal Promosi Kesehatan Indonesia, 11(1):14-27.

Villako, P., Volmer, D., Raal, A.I.N. 2012. General factors influencing purchase of and counselling about prescription and OTC medicines at community pharmacies in Tallinn Estonia. Acta Poloniae Pharmaceutica and Drug Research, 69(2):335340.

Widayati, A. 2013. Swamedikasi di kalangan masyarakat perkotaan di Kota Yogyakarta. Jurnal Farmasi Klinik Indonesia 2(4):145-152. 